\title{
Substrate Directable Heck-Matsuda Reactions: Studies on the Synthesis of 4-Arylprolines
}

\author{
Fernanda G. Finelli, Marla N. Godoi and Carlos Roque D. Correia* \\ Instituto de Química, UNICAMP, CP 6154, CEP 13083-970, Campinas, SP, Brazil \\ *e-mail corresponding author: roque@iqm.unicamp.br
}

Keywords: arenediazonium salt, nonactivated olefins, neuroexcitatory amino acids

\section{INTRODUCTION}

The Heck reaction is a widely used carbon-carbon bond forming process in organic synthesis. An important variant of this reaction developed by Matsuda in 1977 introduced arenediazonium salt as arylating agent. It has emerged as a greener, faster and more practical alternative to the conventional Heck protocols.

In 2007, we presented the application of an efficient regio- and stereoselective Heck-Matsuda (HM) arylation of $\mathrm{N}$-carbomethoxy-L-3-dehydroproline methyl ester (1) with arenediazonium tetrafluoroborates in the syntheses of aryl kainoids with potent neurotoxic activities. ${ }^{2}$ Recently, new studies using arenediazonium salts containing EWG showed an unexpected inversion of the enantioselectivity in these substrate directable HM reactions. Herein we report the details of these investigations and a possible rationalization for this surprising result.

\section{RESULTS AND DISCUSSION}

We started with the preparation of olefin $\mathbf{1}$ in multigram scale from de commercially available trans-4-hydroxyproline as described by Wong (55\% overall yield for 4 steps). Subsequently, we studied the arylation reactions using several arenediazonium salts to test the viability of this protocol and prepare precursors for new prolines and aryl kainoids. The HM reaction afforded the desired 4-arylprolines 2 and 3 in high regio- and stereoselectivities and excellent yield for the reaction with EDG-containing salt and moderate yield for EWG-containing salt (Table 1).

Table 1. HM reactions on synthesis of 4-arylprolines

\begin{tabular}{|c|c|c|c|c|c|}
\hline 1 & $\mathrm{CO}_{2} \mathrm{Me}$ & $\frac{\mathrm{d}(\mathrm{OAc})_{2}}{\mathrm{MeOH},}$ & $\begin{array}{l}\text { n salts } \\
\mathrm{mol} \%\end{array}$ & $\begin{array}{l}\mathrm{CO}_{2} \mathrm{Me} \\
\mathbf{2 - 3}\end{array}$ & \\
\hline \multirow{2}{*}{ entry } & \multirow{2}{*}{$\mathbf{R}$} & \multicolumn{2}{|c|}{$\Delta$ conventional $^{a}$} & \multicolumn{2}{|c|}{$\Delta M^{\prime b}$} \\
\hline & & Time (h) & Yield & Time (min) & Yield \\
\hline 1 & 2-OMe (2) & 12 & $92 \%$ & 12 & $84 \%$ \\
\hline 2 & $4-\mathrm{Br}(3)$ & 5 & $70 \%$ & 25 & $69 \%$ \\
\hline
\end{tabular}

a $60^{\circ} \mathrm{C}, 2$ equiv. of arenediazonium salts. ${ }^{b} 100^{\circ} \mathrm{C}, 2$ equiv. of arenediazonium salts.

$14^{\text {th }}$ Brazilian Meeting on Organic Synthesis $-14^{\text {th }}$ BMOS - September 01-05, 2011-Brasilia, Brazil
As part of our goals, the Heck adduct 3 was employed in the stereocontrolled total syntheses of different neurotoxic aryl kainoids 4-9. These syntheses provided definitive evidence for the stereochemistry of 2-OMe-arylproline 2 (Figure 1). In order to determine the stereochemistry of the Heck arylation with EWG, the arylproline $\mathbf{3}$ was converted to the known arylproline 10, allowing us to assign an unpredicted configuration for 3 .

Figure 1. Preparation of new prolines and aryl kainoids
o-OMeAr,
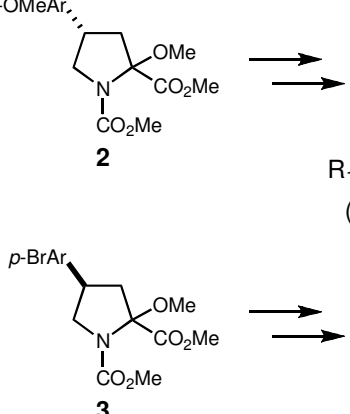

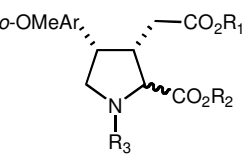

$\mathrm{R}_{1}, \mathrm{R}_{2}, \mathrm{R}_{3}=\mathrm{H}, \mathrm{Me}$ or $\mathrm{CBz}$ (2-R)-4-7 and (2-S)-8-9

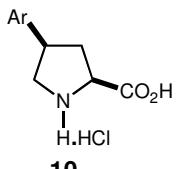

10
This result suggests a possible complexation between the cationic arylpalladium intermediate and the ester group in C2, assisted by the influence of the EWG in the aryl portion, driving the Heck arylation. Moreover, the absolute configuration of the $(4-R)$-arylproline 3 indicates an uncommon trans $\beta$ elimination at the last step of this coupling.

\section{CONCLUSION}

We have observed an unusual substrate-control in the stereochemistry of HM reactions. Our efforts are concentrated on confirming the absolute configuration through X-ray analyses of 4arylprolines with different EWG and EDG. We also intend to evaluate the ee of these reactions.

\section{ACKNOWLEDGEMENTS}

The authors thank the Brazilian Funding Agencies FAPESP and CNPq for financial support.

\section{REFERENCES}

Taylor, J. G.; Moro, A. V.; Correia, C. R. D. Eur. J. Org. Chem. 2011, 1403.

${ }^{2}$ da Silva, K. P.; Godoi, M. N.; Correia, C. R. D. Org. Lett. 2007, 9, 2815. 